\title{
On the Primary Thermal Decomposition Pathways of Hydroxycinnamaldehydes
}

Liang Li ${ }^{l}$, Ruben Van de Vijver ${ }^{l}$, Andreas Eschenbacher ${ }^{l}$, Onur Dogu ${ }^{l}$, Kevin M. Van Geem ${ }^{l *}$

${ }^{1}$ Laboratory for Chemical Technology, Ghent University

Technologiepark 125, 9052 Ghent, Belgium 


\section{Abstract}

Hydroxycinnamaldehyde monomers are important intermediates in the lignin biosynthesis and can be incorporated into plants in large quantities via genetic modification. They are also important products formed during pyrolysis or combustion of lignocellulose. In this work, the decomposition of three hydroxycinnamaldehyde model compounds, cinnamaldehyde, $p$-coumaraldehyde, and coniferaldehyde, was studied in a micropyrolysis reactor equipped with an online GC $\times$ GC-FID/TOF-MS coupled with a customized GC for the on-line analysis of all the pyrolysis vapors including permanent gases. The vaporization or sublimation process of these model compounds in the reactor was fitted well based on the experimental time-resolved data. The dominating initial decomposition pathways were elucidated from a first-principles based kinetic model and using rate of production analysis. For cinnamaldehyde (at 773$1123 \mathrm{~K}$ ) and $p$-coumaraldehyde (at $873-1123 \mathrm{~K}$ ), the concerted decarbonylation reactions in the condensed phase are determining the initial decomposition, with almost no contribution from radical chemistry. For coniferaldehyde (at $773-1023 \mathrm{~K})$, the homolysis of O-methyl $\left(\mathrm{O}-\mathrm{CH}_{3}\right)$ bond initiates a radical chain mechanism at temperatures above $773 \mathrm{~K}$, and the $\mathrm{H}$-atom abstraction on the aldehyde group is the most dominant consumption pathway at high temperatures. The presence of methoxy groups on the aromatic rings accelerates the decomposition of hydroxycinnamaldehydes. Models that do not account for these important structural differences will have difficulties to predict the decomposition of real lignocellulosic biomass. 


\section{Introduction}

Since 2019 several new biomass fast pyrolysis plants were commissioned that produced bio-oils with high yields (up to 75 wt.\%) (1). Bio-oils are complex mixtures consisting of water and hundreds of organic compounds such as several lignin-derived aromatic chemicals which are of commercial importance (2-7). As one of the three components of lignocellulosic biomass, lignin accounts for $18-40 \mathrm{wt} . \%$ of the dry wood and it is different for other types of biomass (8). It is a phenolic random polymer generated by dehydrogenative polymerization of monolignols, $p$-coumaryl, coniferyl and sinapyl alcohols, which are synthesized in plants by enzymatic pathways starting from phenylalanine (9-10). Due to the complexity and irregularity of the lignin structure, model compounds which represent the essential reactive moieties of lignin or an important component of the pyrolysis oil are often selected and pyrolyzed to examine and understand the pyrolysis behavior of lignin (11-15). Pyrolysis is a very complicated process that usually includes hundreds or thousands of reactions and hundreds of species (16-18). Detailed kinetic modeling is used as a tool to elucidate the underlying chemistry of lignin pyrolysis and to understand the influence of process conditions on the yields of various products (19-21). The kinetic models of the decomposition of phenol (22), anisole (23-25) and guaiacol (26-27) have already been proposed. For the above mentioned monolignols, their pyrolysis chemistry is typically elucidated based on a combination of measuring the varying product distribution at different conditions and chemical intuition (28-31). Today detailed kinetic models of other lignin model compounds are lacking. In addition, the pyrolysis of model compounds is usually performed in the gas phase while for lignin or biomass pyrolysis the liquid/solid-phase reactions and the competition between different phases are non-negligible (32-36).

$P$-coumaraldehyde (PA) and coniferaldehyde (CoA), which are phenolic derivatives of cinnamaldehyde (CA), as the intermediates, play an important role in the biosynthesis of their corresponding monolignols (37-38). They can be largely incorporated into the lignin structure via genetic engineering. For instance, 
coniferaldehyde-derived units were enriched in plants through the downregulation of enzyme activity of CINNAMYL ALCOHOL DEHYDROGENASE (CAD) (39-40). Recent in-house studies have demonstrated genetic engineering as a potential tool to alter the lignin composition of biomass for the increased production of value-added chemicals via fast pyrolysis (41-43). Besides, these hydroxycinnamaldehydes are also major products from the pyrolysis or combustion of lignin or the above monolignols. For instance, cinnamaldehyde and coniferaldehyde are reported as the major products from the pyrolysis of cinnamyl alcohol (29) and G-lignin (guaiacyl subunits) (28), respectively.

In this study, we have tried to improve chemical understanding of lignin pyrolysis by using CA, PA and CoA as lignin model compounds and studying their decomposition. To the best of our knowledge, their pyrolysis behaviors have rarely been reported, except one simple case on CA (44) and CoA (45), respectively. All the pyrolysis products are quantified using a comprehensive set of analytic instruments that allows to close the mass and molar balances with a high accuracy. In conjunction with a kinetic model and reactor modeling in CANTERA (46), the present work aims at identifying the major thermal decomposition routes and mechanisms of hydroxycinnamaldehydes .

\section{Materials and Methods}

\subsection{Model compounds}

The model compounds used in this study are CA (purity $\geq 95 \%$, CAS: 104-55-2) and CoA (purity $\geq 98 \%$, CAS: 458-36-6). They were purchased from Sigma Aldrich, Inc. PA (purity $\geq 98 \%$, CAS: 2538-87-6) was procured from Toronto Research Chemicals Inc. The molecular structures of these studied compounds, together with the bond dissociation energies within each compound, are shown in Figure 1. The basic physical properties such as melting and boiling points and the pyrolysis temperatures are summarized in Table 1. At room temperature, $\mathrm{CA}$ is a liquid while the other compounds are solid. Due to the low loading amounts of $100 \mu \mathrm{g}$ and the pyrolysis temperatures being well above their boiling points, the model 
compounds are expected to vaporize or sublime directly into the gas phase instead of undergoing an intermediate state. This has been verified by so-called vaporization experiments in which the reactor effluent was continuously followed using the time-of-flight mass spectrometer (TOF-MS).

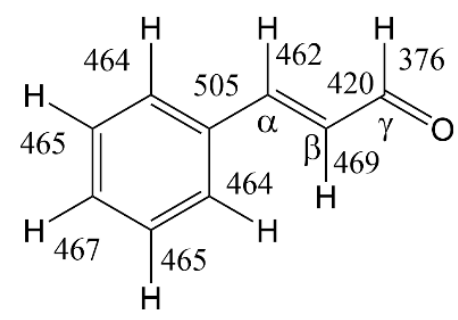

CA

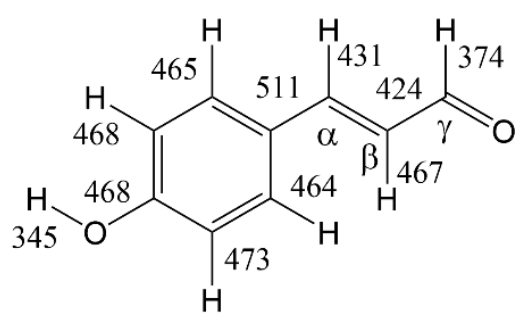

PA

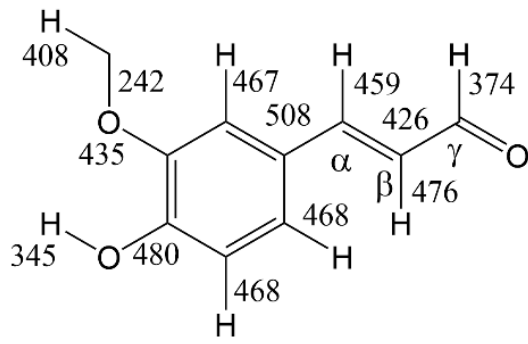

$\mathrm{CoA}$

Figure 1. Molecular structures of the model compounds with their corresponding BDEs in $\mathrm{kJ} / \mathrm{mol}$ calculated at CBS-QB3 level of theory.

Table 1. Melting and boiling points of model compounds and the corresponding pyrolysis temperatures.

\begin{tabular}{llll}
\hline Model compounds & Melting point (K) & ${\text { Boiling point }(\mathbf{K})^{\mathbf{a}}}^{\mathbf{2}}$ & Pyrolysis temperature (K) \\
\hline Cinnamaldehyde (CA) & 265 & 521 & 773 to 1123 \\
$P$-coumaraldehyde (PA) & 413 & 582 & 873 to 1123 \\
Coniferaldehyde (CoA) & 353 & 612 & 773 to 1023 \\
\hline
\end{tabular}

${ }^{\text {a }}$ Data from ChemSpider (47)

\subsection{Fast pyrolysis apparatus and online analysis of product vapors}

The pyrolysis experiments were performed in a micro-pyrolysis unit consisting of two sections, viz. reactor and analytics (Figure 2a) (48). The reactor is a double-shot tandem micropyrolyzer (Frontier Labs, Japan) with two reactors connected in series. In this study, only the first reactor with a deactivated quartz tube was used to study liquid or solid to gas transformations of hydroxycinnamaldehydes under pyrolysis conditions (at $773-1123 \mathrm{~K}$ and $2.8 \mathrm{~atm}$ ). The quartz tube has an internal diameter of $0.004 \mathrm{~m}$ for the initial length of $0.075 \mathrm{~m}$ and $0.002 \mathrm{~m}$ for the remaining length of $0.045 \mathrm{~m}$. In this work, $100 \pm 10 \mu \mathrm{g}$ of samples were loaded in a shallow eco-cup (0.004 m length) and inserted into the reactor via a dropping 
device. After mounting the sample cup to the sample holder on top of the reactor, the sample cup was purged for $30 \mathrm{~s}$ using the carrier gas $(\mathrm{He})$ and then dropped into the reactor at a pre-set pyrolysis temperature. A split flow of $210 \mathrm{~mL} / \mathrm{min}$ with a split ratio of 100:1 was maintained to sweep the sample vapors from the reactor into the $\mathrm{GC}$ inlet that was maintained at $573 \mathrm{~K}$. The volatilized products then entered a guard column where the products (except, $\mathrm{CO}, \mathrm{CH}_{4}$, and $\mathrm{H}_{2}$ ) were trapped with a micro-jet cryotrap cooled with liquid nitrogen at $77 \mathrm{~K}$. After 5 minutes, the cold trap was switched off automatically, allowing the trapped products to be released by heating up to the oven temperature. The oven temperature program started from $313 \mathrm{~K}(6 \mathrm{~min})$ and the temperature was increased to $573 \mathrm{~K}(2 \mathrm{~min})$ at a $5 \mathrm{~K} / \mathrm{min}$ heating rate. The effluent was released and divided into two streams for the simultaneous analysis of permanent gases and water in a customized light oxygenates analyzer (LOA) (Trace 1300), and other products along with unreacted model compounds in the $\mathrm{GC} \times \mathrm{GC}-\mathrm{FID} / \mathrm{TOF}-\mathrm{MS}$. The customized LOA GC consists of a valve oven with a series of electrical depressurization valves (ELDV) that are switched at pre-determined times to regulate the injection of gases onto different GC columns (see the supplementary information, SI). The GC $\times$ GC (Thermo Scientific, Trace GC) consists of a Rtx-1 PONA as the $1^{\text {st }}$ column $(50 \mathrm{~m})$, a BPX-5 as the $2^{\text {nd }}$ column $(2 \mathrm{~m})$, and a two-stage modulator with liquid $\mathrm{CO}_{2}$ jets to separate the products based on boiling points and polarity respectively. Details of the quantification of GC $\times$ GC data have been discussed elsewhere (49-50).

Prior to the pyrolysis experiments, time-resolved experiments were performed. For these experiments, the outlet of the reactor stream was directly injected into the TOF-MS with its restriction column installed in the split/split-less injector. The guard column previously attached to the reactor was connected to the PTV injector because the set of columns used for the $\mathrm{GC} \times \mathrm{GC}$ experiments, also require a helium flow through them since they were still in the GC oven. The schematic of the configuration is shown in Figure $2 b$. For the pyrolysis tests, a TOF-MS (BenchTOF-Select, Markes International) was connected to identify the products with an ionization voltage of $-20 \mathrm{eV}$. In this voltage, the model compounds and their primary 
products have very little fragmentation and enhanced molecular ions in the TOF-MS, which helps with their precise identification. A flame ionization detector (FID, Thermo Scientific) was used to quantify the product yields. Three model compounds, CA, PA, and CoA, were calibrated externally and all the other products detected by FID were quantified according to the effective carbon number method (51). $\mathrm{CO}, \mathrm{CO}_{2}$ and water observed on the customized LOA GC were quantified based on external calibration curves which were obtained by injecting different masses of calcium oxalate monohydrate (Sigma-Aldrich $98 \%$ purity) into the pyrolysis reactor at $1123 \mathrm{~K}$. Each experiment was performed at least two times at the same condition in order to calculate the standard error, which was less than $10 \%$ relative for the reactants and major products. 
(a)

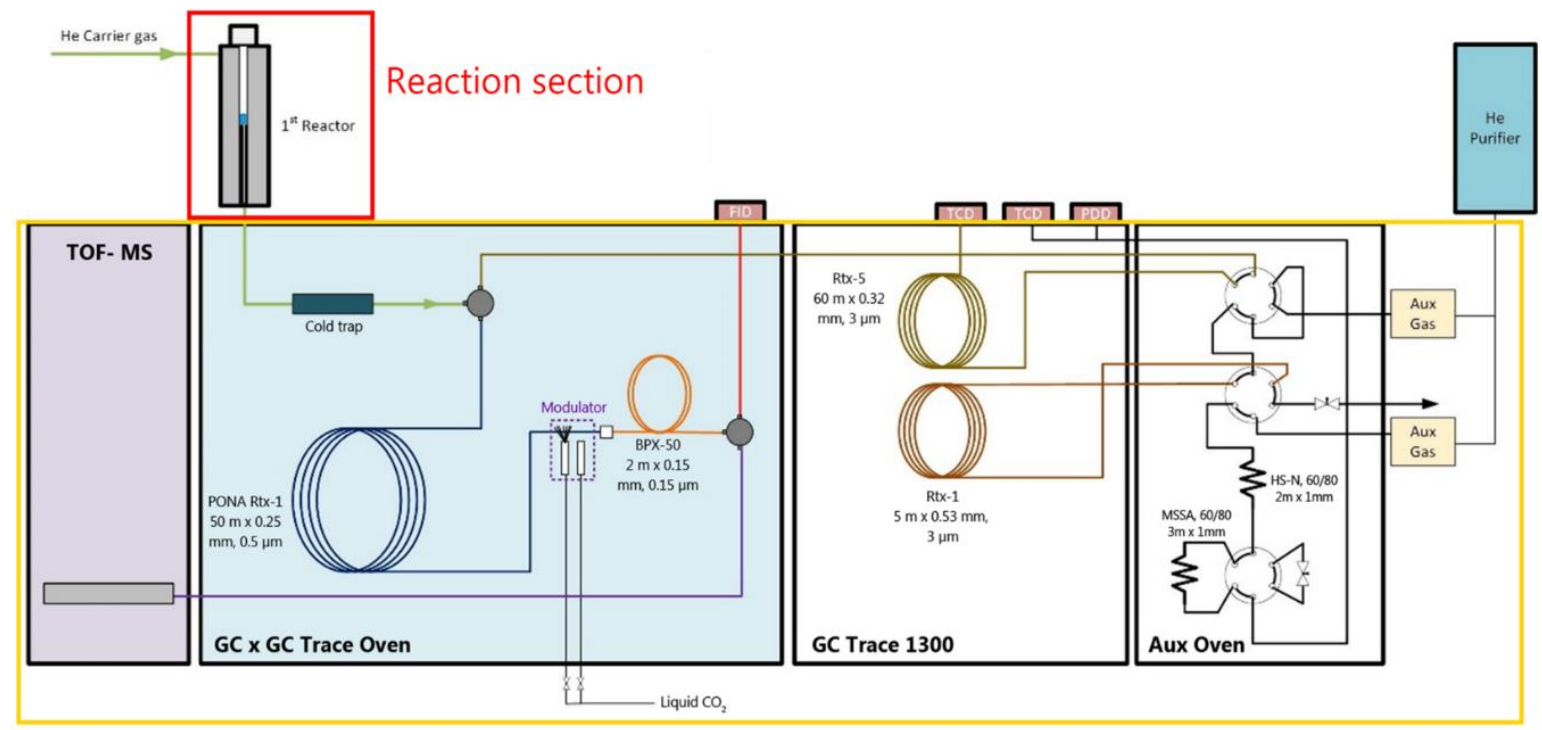

Analytics section

(b)

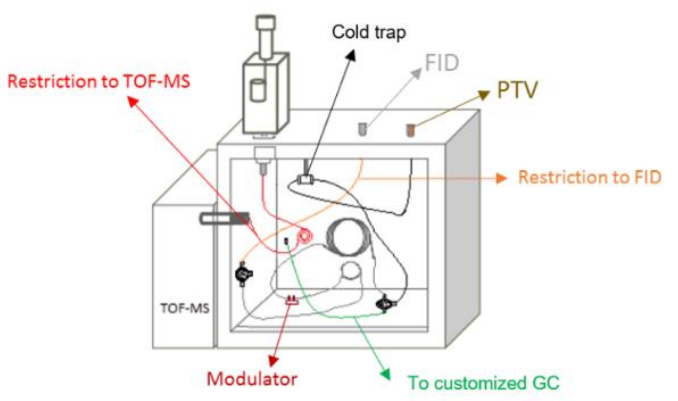

Figure 2. (a) Schematic diagram of the micropyrolyzer with a comprehensive analytical section. (b) Schematic diagram of the configuration of time-resolved experiments.

\subsection{Theoretical Calculations and Reactor Modeling}

The bond dissociation energies (BDEs) of the three model compounds (Figure 1), were calculated on the high-performance supercomputer at Ghent University at the CBS-QB3 level of theory (52) as implemented in Gaussian 16 (53) next to the thermodynamic properties of all the species and several key reaction rate coefficients. For all molecules, radicals and transition states, the lowest-energy conformers 
are determined by performing calculations for all conformers. BDEs can be used as an qualitative assessment of the relative importance of the potential homolysis reactions.

BDEs analysis (Figure 1) shows that the weakest bonds of CA, PA and CoA are $\mathrm{C} \gamma-\mathrm{H}(376 \mathrm{~kJ} / \mathrm{mol}), \mathrm{O}-\mathrm{H}$ $(345 \mathrm{~kJ} / \mathrm{mol})$ and $\mathrm{O}-\mathrm{CH}_{3}(242 \mathrm{~kJ} / \mathrm{mol})$ bonds, respectively. Their breaking is supposed to be the first step of the corresponding reactants decomposition via the radical mechanism. In addition, as reported in some literatures (54-56), the introduction of functional groups on an aromatic ring have a strong effect on the BDEs of vicinal bonds. Such proximity effects were also found in our study. For example, the insertion of a methoxy group in PA molecule increases the adjacent $\mathrm{HO}-\mathrm{Ph}$ bond dissociation energies by about $12 \mathrm{~kJ} / \mathrm{mol}$. This trend is agreement with the BDEs of phenol and guaiacol analyzed by Pelucchi et al (56). The kinetic mechanisms involving the primary chain initiation and propagation reactions for the thermal decomposition of CA and PA and CoA have been developed on the basis of their experimental primary products. These primary reactions, including unimolecular initiations, H-atom abstraction, and radical decomposition reactions, are listed in Table 2-4. Here, the vaporization or sublimation process was treated with first order kinetics, and the corresponding rate coefficients were fitted based on the time-resolved experimental data. The decarbonylation reaction was modeled to proceed both in the liquid or solid phase as well as in the gas phase. All the radical reactions occur only in the gas phase. The last columns of table 2-4 show the source of rate constants of these reactions. All mechanism files with the computational data can be found in SI in CHEMKIN format.

Taking CoA pyrolysis as an example for further description, the kinetic model involves 4 reactions and 3 species in the solid phase, and 11 reactions and 12 species in the gas phase, as shown in table 4 . Arrhenius parameters of the decarbonylation reactions estimated by RMG-Py rate rules were taken from the kinetic database implemented in MIT's Reaction Mechanism Generator (RMG), an open source software package for automatic mechanism generation (57). Unimolecular initiations include the breaking of $\mathrm{O}-\mathrm{CH}_{3}$ bond and $\mathrm{C}_{\beta}-\mathrm{C} \gamma$ bond, as well as the loss of an $\mathrm{H}$ atom from aldehyde and hydroxyl groups (gas phase reactions 
1-4). Rate parameters of the breaking of the weakest $\mathrm{O}-\mathrm{CH}_{3}$ bond leading to phenoxy-type and $\mathrm{CH}_{3}$ radicals were extracted from the analogous reaction of guaiacol to form hydroxyphenoxy and $\mathrm{CH}_{3}$ radicals (56). Homolysis of $\mathrm{C} \gamma-\mathrm{H}$ and $\mathrm{C}_{\beta}-\mathrm{C} \gamma$ bonds, and $\mathrm{O}-\mathrm{H}$ bond was supposed similar to those in $\mathrm{C}_{2} \mathrm{H}_{3} \mathrm{CHO}$ (58), and phenol (56), respectively. Bimolecular initiations by H-atom abstractions from aldehyde and hydroxyl groups by $\mathrm{CH}_{3}$ radicals (reaction 5 and 6) were estimated by analogy with the reactions of but2-enal (59) and phenol (60). The formed radical $R(C 9)$ (shown in Figure 7) can decompose into CO and 4-vinyl guaiacol radicals (reaction 7), with the rate constant estimated from the similar reaction of $\mathrm{SC}_{3} \mathrm{H}_{5} \mathrm{CO}$ radicals leading to $\mathrm{CO}$ and $\mathrm{SC}_{3} \mathrm{H}_{5}$ radicals (59). Similar to $\mathrm{CH}_{3}$ radicals, the produced 4-vinyl guaiacol radicals can also react with CoA via $\mathrm{H}$-atom abstractions from aldehyde and hydroxyl groups (reaction 8 and 9). Their rate coefficients were derived from the analogous reactions (the reaction equations are $\mathrm{C}_{2} \mathrm{H}_{3}+\mathrm{C}_{2} \mathrm{H}_{3} \mathrm{CHO}=\mathrm{C}_{2} \mathrm{H}_{4}+\mathrm{C}_{2} \mathrm{H}_{3} \mathrm{CO}$, and $\mathrm{C}_{2} \mathrm{H}_{3}+$ phenol $=\mathrm{C}_{2} \mathrm{H}_{4}+$ phenoxy), which were theoretically calculated at the CBS-QB3 level. Here, the A-factor of the former was multiplied by 2, and it was divided by 2 for the latter, which is in the range of uncertainty of the correlation used. For the CA and PA pyrolysis mechanisms, the rate constants of the decarbonylation reactions derived from RMG were also adjusted within a factor of 2.

Table 2. Rate constants for primary reactions of CA decomposition and references. Rate constants are in the form $\mathrm{AT}^{\mathrm{n}} \exp (-\mathrm{Ea} / \mathrm{RT})$ in cm, mol, s, and $\mathrm{kJ}$ units.

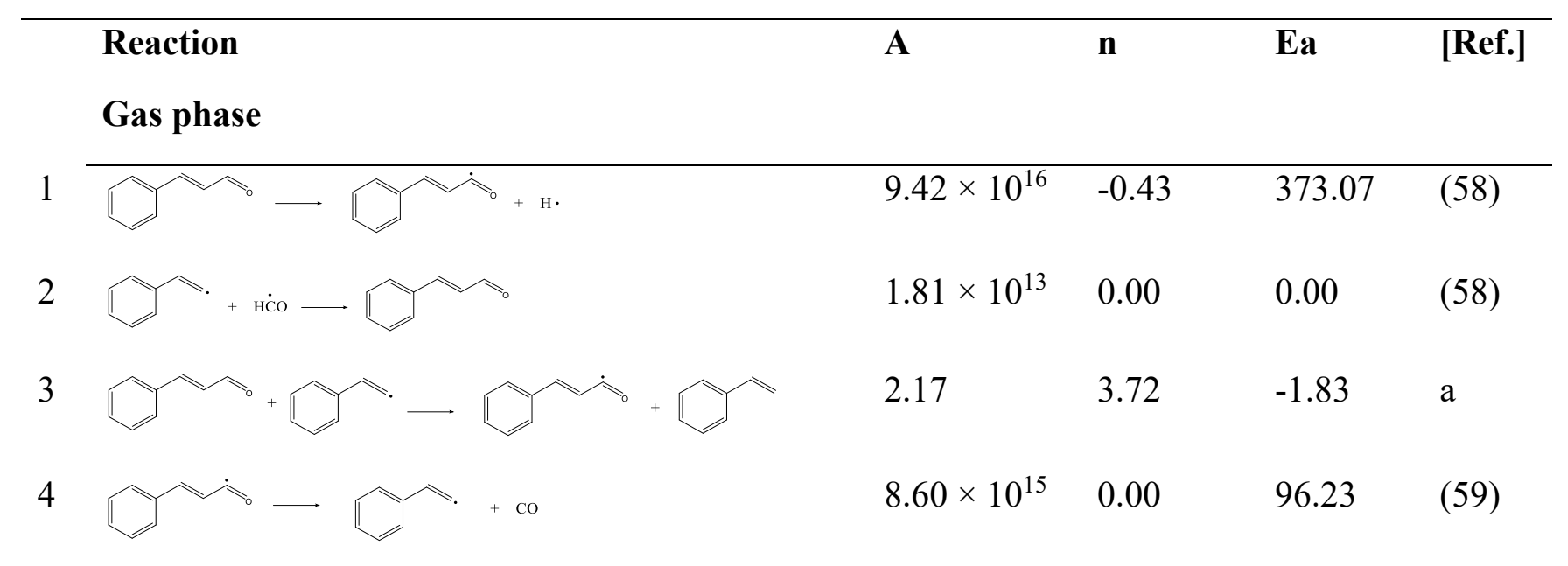




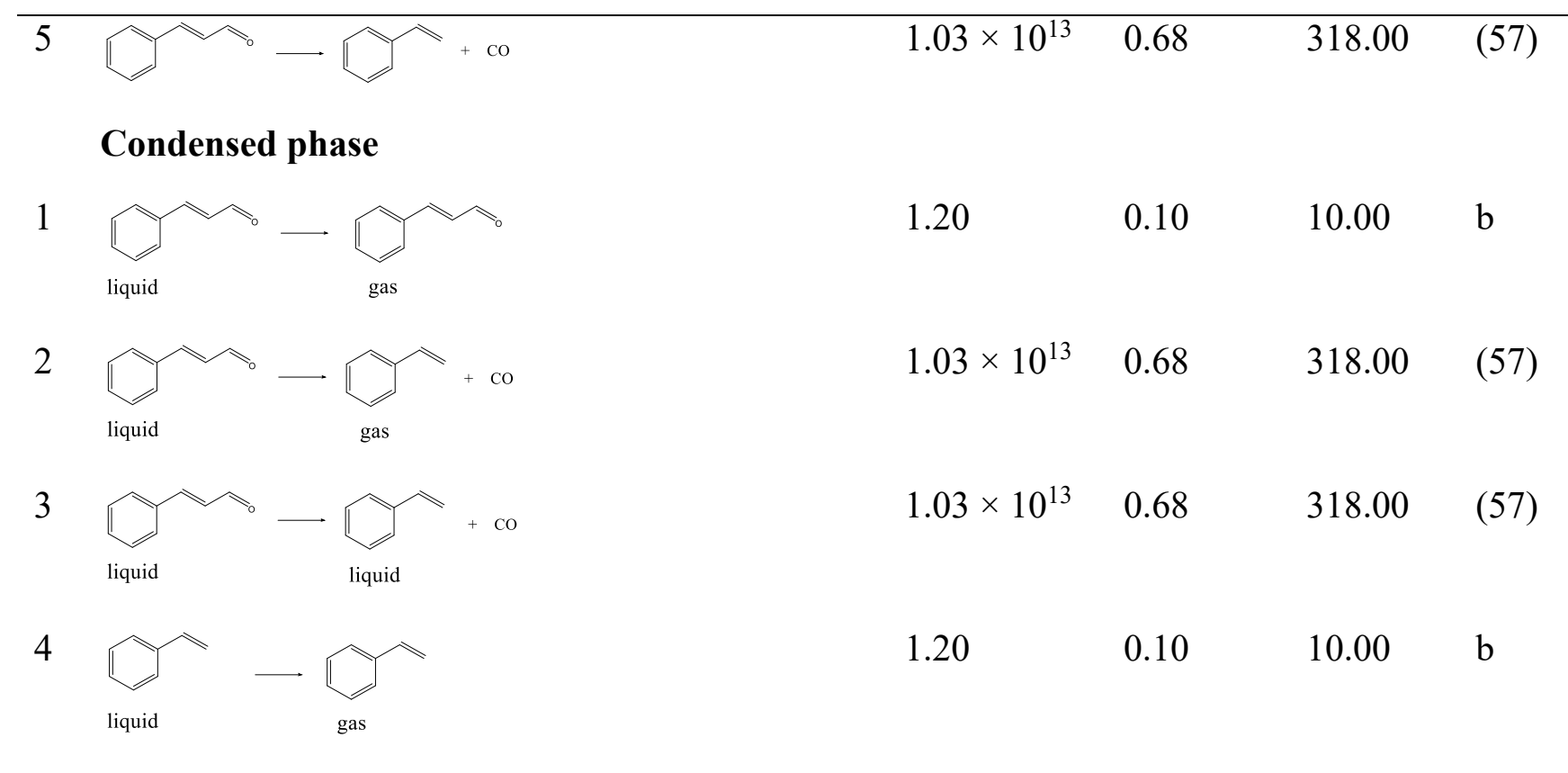

${ }^{\mathrm{a}}$ analogous reactions calculated at CBS-QB3 level

${ }^{b}$ fitted rate parameters based on the experimental time-resolved data

Table 3. Rate constants for primary reactions of PA decomposition and references. Rate constants are in the form $\mathrm{AT}^{\mathrm{n}} \exp (-\mathrm{Ea} / \mathrm{RT})$ in $\mathrm{cm}, \mathrm{mol}, \mathrm{s}$, and $\mathrm{kJ}$ units.

[Ref.]




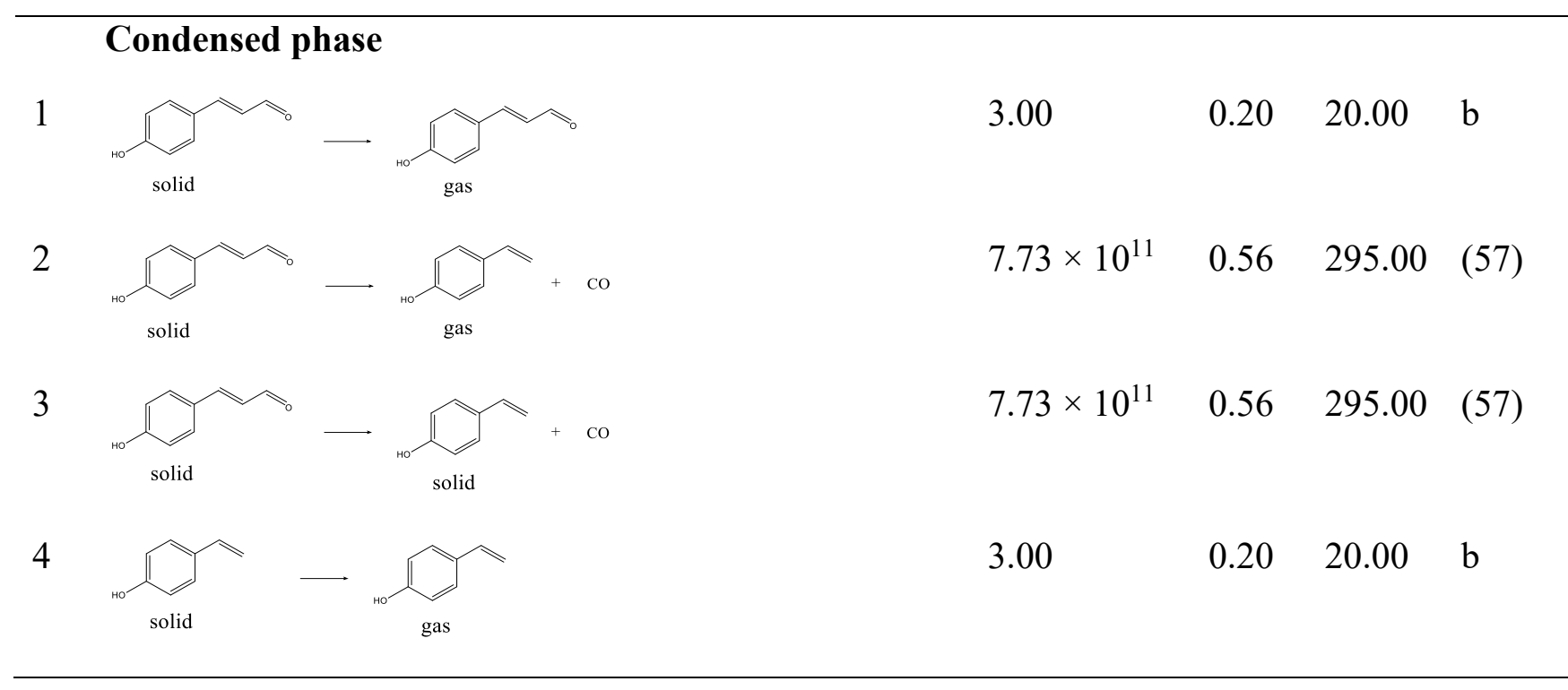

Table 4. Rate constants for primary reactions of CoA decomposition and references. Rate constants are in the form $\mathrm{AT}^{\mathrm{n}} \exp (-\mathrm{Ea} / \mathrm{RT})$ in $\mathrm{cm}, \mathrm{mol}, \mathrm{s}$, and $\mathrm{kJ}$ units.

[Ref.]




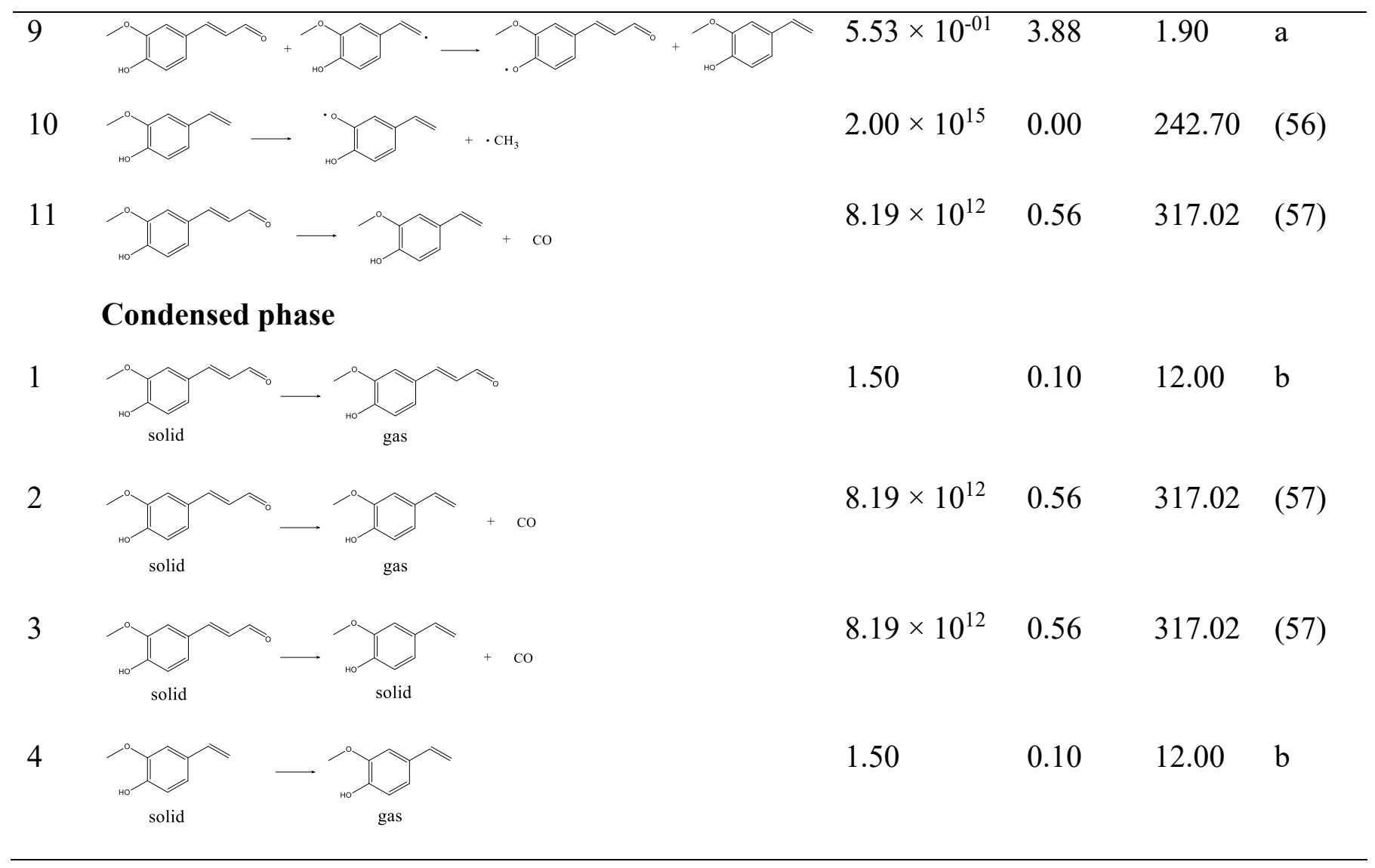

The reactor simulations in this work are performed using a semi-batch model in the Python interface of the CANTERA software, version 2.4 (46). The model equations are given below:

A mass balance is made for the reactor:

$$
\begin{gathered}
\text { accumulation }=\text { in-out }+ \text { production } \\
\frac{d x_{j}(t)}{d t} n_{t o t}(t)=F_{j, \text { in }}(t)-F_{j, \text { out }}(t)+R_{j}(t) n_{t o t}(t)
\end{gathered}
$$

where $x_{j}$ is the molar fraction, $n_{t o t}$ the total number of moles of species $(\mathrm{mol}), F_{j, \text { in }}$ the molar flow rate at the inlet $\left(\mathrm{mol} \mathrm{s}^{-1}\right), F_{j, \text { out }}$ the molar flow rate at the outlet $\left(\mathrm{mol} \mathrm{s}^{-1}\right) . R_{j}$ is the net production rate $\left(\mathrm{s}^{-1}\right)$ for species $\mathrm{j}$, which is calculated as the sum of the reaction rates for the reactions where $\mathrm{j}$ is formed or consumed:

$$
R j(t)=\sum_{i=1}^{n} v_{i j} k_{i} x_{i}(t)
$$


In this equation $n$ is the number of reactions which depends on the used kinetic scheme, $v_{i j}$ the stoichiometric coefficient for species $\mathrm{j}$ in reaction $\mathrm{i}, k_{i}$ the reaction rate coefficient $\left(\mathrm{s}^{-1}\right)$ and $x_{i}$ the molar fraction of the reactant in reaction $\mathrm{i}$.

For all gaseous reaction products, the inlet flow rate is zero as they are all produced inside the reactor, and none of them enters the reactor as a feed. Furthermore, it is assumed that no accumulation occurs as the produced gaseous products are swept away immediately by the carrier gas. Therefore, equation (1) becomes:

$$
0=0-F_{j, \text { out }}(t)+R_{j}(t) n_{\text {tot }}(t)
$$

The outlet molar flow rate for all gaseous species is equal to the molar flow rate inside the reactor:

$$
F_{j, \text { out }}(t)=F_{j}(t)=R_{j}(t) n_{\text {tot }}(t)
$$

where $F j(t)$ is the molar flow rate of species $\mathrm{j}$ at time $\mathrm{t}$ inside the reactor.

Both the inlet and outlet flow rates are zero for solid species remaining in the reactor, and equation (1) simplifies for those species to:

$$
\frac{d x_{j}(t)}{d t} n_{t o t}(t)=R_{j}(t) n_{t o t}(t)
$$

More details on the modeling of the reactor can be found in the work of Toraman (61) and in Text S2.

\section{Results and discussion}

\subsection{Time-resolved experiments}

The raw TOF-MS data was exported for the full spectrum. To have a better comparison with the simulations, the intensity of the experimental peaks were firstly normalized to take into account the different sample weights, then were multiplied by the specific factors, and the delay time caused by the transport from the reactor to the detector was eliminated. Experimental time-resolved profiles for CA, PA and CoA pyrolysis at different temperatures are shown in symbols in Figure 3. The X-axis represents the total residence time or pyrolysis time which can be quantified as the time when the pyrolysis products are 
no longer detected in the reactor outlet and the peaks approach zero. The Y-axis represents the total mole fraction of all species in the presence of helium carrier gas. For each model compound, the peak maxima drift towards the left with an increasing temperature, implying faster vaporization or sublimation and reaction. Compared the profiles of different model compounds, the total residence times increase in order of PA, CA and CoA. The order of PA and CA is not expected due to the higher boiling point of the former. A reasonable explanation is that solid PA powders have a higher exposed surface area than liquid CA, which leads to faster sublimation of PA. Based on the experimental time-resolved profiles, the simulated profiles (lines in Figure 3) at the corresponding temperatures are obtained by adjusting the rate coefficients of the vaporization or sublimation. Figure 3 shows that simulations have a similar profile shape and residence time compared to the experiments, which helps to better understand the competition between vaporization or sublimation and chemical reactions in the reactor at different pyrolysis temperatures. 

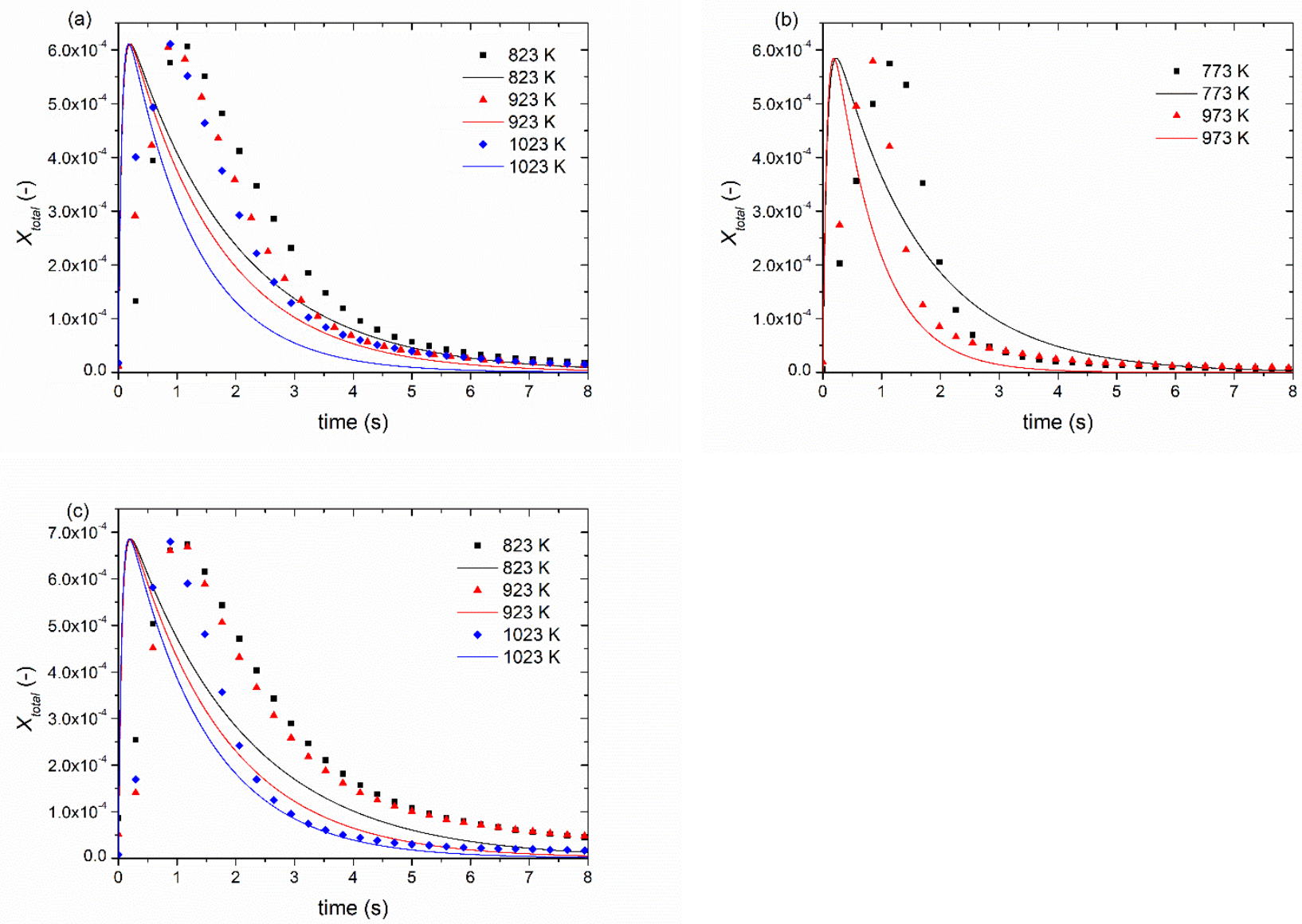

Figure 3. Experimental (symbols) and simulated (lines) time-resolved profiles of (a) CA, (b) PA and (c) CoA pyrolysis at different temperatures.

\subsection{Thermal degradation behavior of CA and PA}

Figure $4 \mathrm{a}$ shows the evolution of the conversion of CA between 773 to $1123 \mathrm{~K}$. There is no conversion observed at $773 \mathrm{~K}$. Above $823 \mathrm{~K}$, CA mainly decomposes into CO, styrene, cis-CA, phenylethyne and dimers of styrene such as stilbene and 1,4-diphenyl-1,3-butadiene whose profiles are displayed in Figure 4b. $\sim 90 \%$ CA conversion was reached at $1123 \mathrm{~K}$. At around 30\% CA conversion, equal mole fractions of styrene and cis-CA were observed which suggests that isomerization may compete with the reaction leading to styrene at low temperatures. Above this conversion, the mole fractions of $\mathrm{CO}$ and styrene increase approximately linearly from $10.2 \%$ to $43.2 \%$, and $7.1 \%$ to $25.9 \%$ respectively with increasing 
CA conversion. This difference of the experimental profiles between $\mathrm{CO}$ and styrene may result from the recombination of styrene radicals leading to styrene dimers that were observed experimentally at high temperatures. Besides, several minor products such as benzene, toluene, benzaldehyde, benzeneacetaldehyde and 2-propenyl benzene were also observed experimentally at temperatures above $1023 \mathrm{~K}$, which are probably formed via radical reactions. This suggests the existence of radical chemistry only at elevated temperatures, which is not dominant for the initial decomposition of CA. Figure 4 (a) and (b) also present the model predictions of CA and primary products of styrene and CO using CANTERA. The trends are well in agreement with the experimental data. The CA conversion is underestimated, but the mole fraction of $\mathrm{CO}$ versus the CA conversion can be predicted well. This may be caused by the less accurate kinetic parameters of the decarbonylation reaction of CA under our experimental conditions.

CA mainly decomposes into styrene and $\mathrm{CO}$, which can happen through two pathways. The first pathway is a decarbonylation reaction via the concerted unimolecular pathway with the activation energy of 316 $\mathrm{kJ} / \mathrm{mol}$. This reaction can occur in the liquid and gas phase. Another pathway is the homolysis of the weakest bond $\mathrm{C} \gamma-\mathrm{H}$ with bond dissociation energy (BDE) of $376 \mathrm{~kJ} / \mathrm{mol}$ (Figure 1), followed by a series of radical reactions. Presumably the former pathway with a lower energy barrier dominates at low temperatures. A rate of production (ROP) analysis performed at $1073 \mathrm{~K}$ for CA pyrolysis is illustrated in Figure 5 (a). The simulated conversion rate of the reactant is $58.6 \%$ at this temperature. Initially the vaporization of liquid $\mathrm{CA}$ is in clear competition with the concerted decarbonylation reaction occurring in the liquid phase, which can directly lead to $\mathrm{CO}$ and gas styrene, or liquid styrene which then evaporates into the gas phase. Both paths have the same kinetic parameters and account for the same ratio $(25.0 \%)$ of the total consumption of liquid CA. The remaining $49.9 \%$ liquid CA evaporates into the gas phase, and then almost all of them are recovered. Here the concerted reaction and radical chemistry in the gas phase are extremely limited due to the short residence time (about $0.2 \mathrm{~s}$ compared to the total residence time of $4 \mathrm{~s})$ and the high $\mathrm{BDE}$ of $\mathrm{C} \gamma-\mathrm{H}(376 \mathrm{~kJ} / \mathrm{mol})$. 

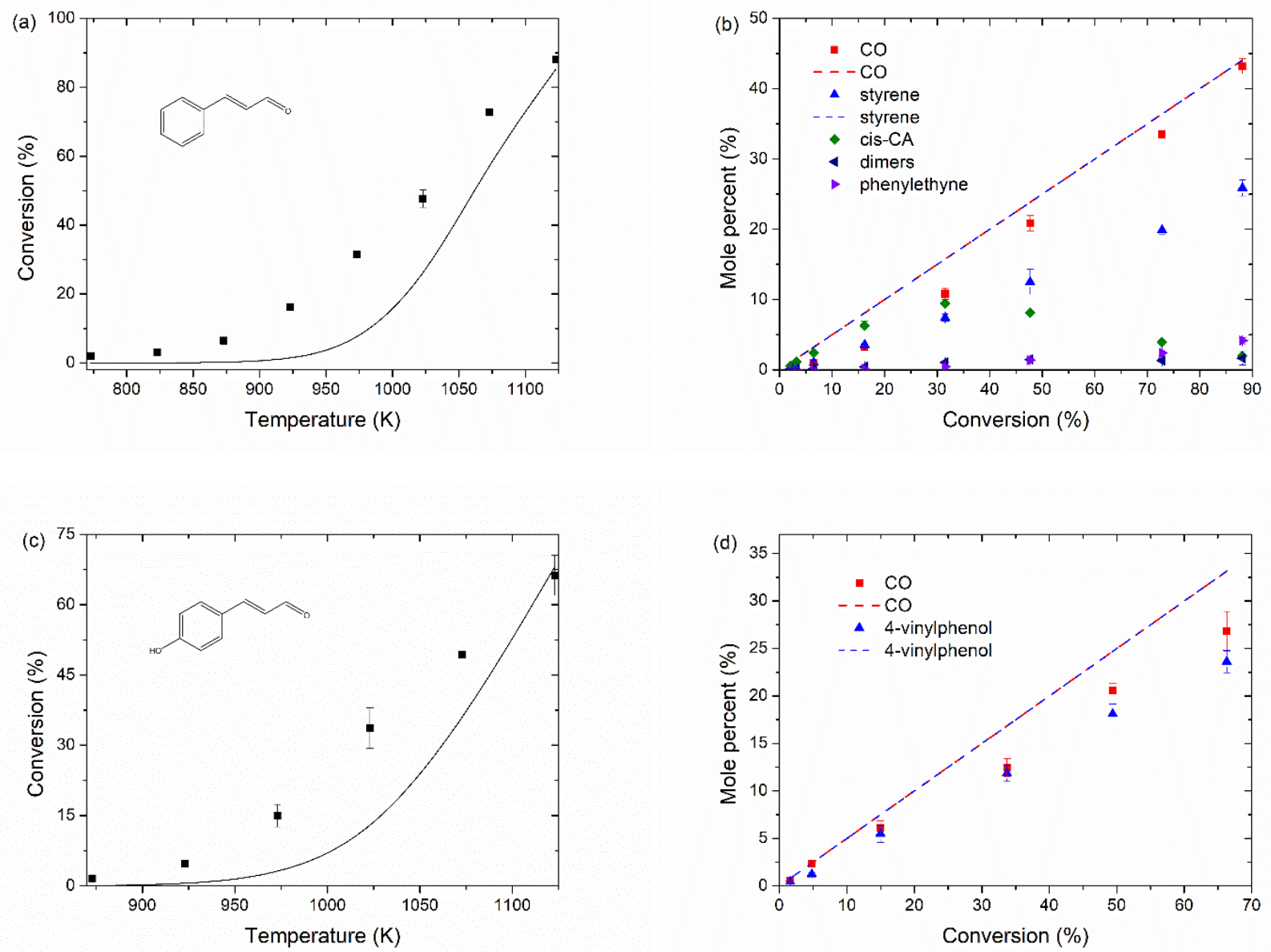

Figure 4. Experimental (symbols) and simulated (lines) conversion of (a) CA and (c) PA versus reactor temperature, and yields of their respective primary products ( $b$ and d). Simulations were performed with CANTERA using in-house developed semi-batch model.

Figure 4 (c) and (d) present the conversion of PA versus reactor temperature, and yields of the corresponding primary products, 4-vinylphenol and $\mathrm{CO}$. Compared with the conversion profile of CA, PA with one more hydroxyl group on aromatic ring seems less reactive, which is due to the shorter residence time of PA according to the results of time-resolved experiments. Similar to the model predictions of CA, the underestimation of PA conversion and better predicted mole fractions of $\mathrm{CO}$ and 4-vinylphenol versus PA conversion, means the kinetics of the main decomposition pathway leading to them could be further optimized to adapt to the current experimental conditions. In the development of the PA model, the above 
mentioned two pathways in CA decomposition were considered. In addition, the homolysis of $\mathrm{O}-\mathrm{H}$ bond with the lowest BDE of $345 \mathrm{~kJ} / \mathrm{mol}$ and the radical chemistry of the forming phenoxy species were included. A similar ROP analysis was done at $1073 \mathrm{~K}$ as shown in Figure 5b. $20.8 \%$ solid PA is consumed via concerted decarbonylation reaction in the condensed phase, and the rest sublimates into the gas phase. Similar to CA pyrolysis, the reactions in the gas phase seem to have no contribution for the consumption of the reactant. Note that in this model, there is no intermediate state in the process of phase transition, as discussed above. Although some intermediate stages may exist, they are only for a very small amount of solids, which has little effect on the simulation results. In addition, the fitted rate constant of phase change such as vaporization and sublimation is higher than that of concerted decarbonylation reaction. As ratedetermining step, the latter can also occur in every intermediate state. 
(a)<smiles>O=C/C=C/c1ccccc1</smiles><smiles>CCc1ccccc1</smiles>

\section{gas phase}

condensed phase
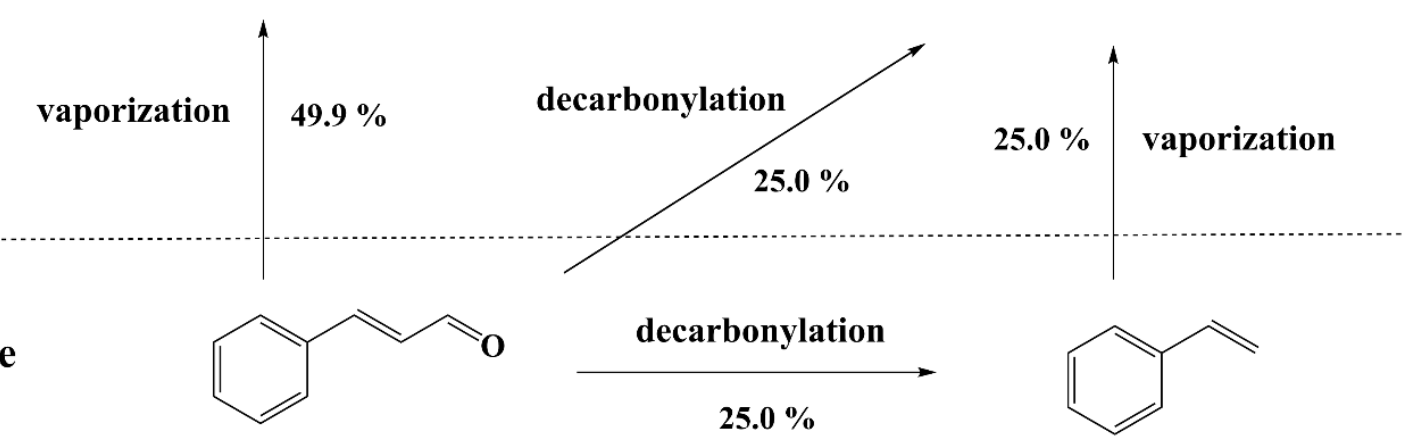

(b)

gas phase<smiles>O=C/C=C/c1ccc(O)cc1</smiles><smiles>C=Cc1ccc(O)cc1</smiles>
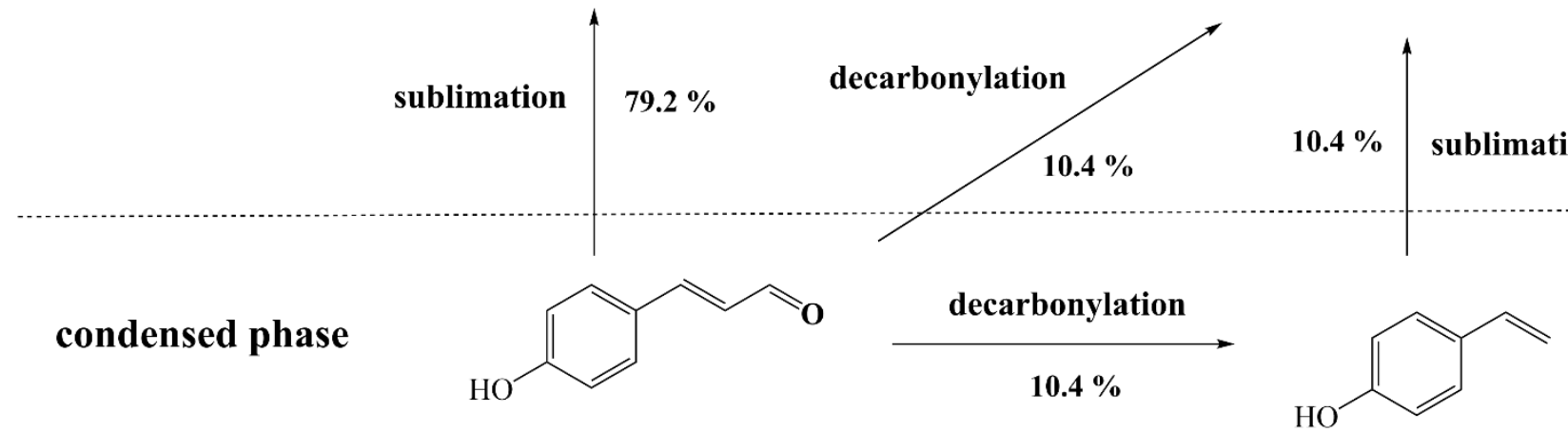

Figure 5. Rate of production analysis for (a) CA and (b) PA pyrolysis at $1023 \mathrm{~K}$ and $2.8 \mathrm{~atm}$. Percentages (numbers associated with arrows) on a reaction path show the reaction rate relative to the consumption of (a) liquid CA and (b) solid PA.

\subsection{Thermal degradation behavior of CoA}

The homolysis of O-methyl $\left(\mathrm{O}-\mathrm{CH}_{3}\right)$ bond has been known as the initial step in the thermal decomposition of simple aromatics such as anisole and guaiacol. In $\mathrm{CoA}$, the $\mathrm{O}-\mathrm{CH}_{3}$ bond has the lowest $\mathrm{BDE}$ of 242 $\mathrm{kJ} / \mathrm{mol}$ which is lower than the energy barrier of concerted decarbonylation, $316 \mathrm{~kJ} / \mathrm{mol}$. Therefore, the fission of the weak $\mathrm{O}-\mathrm{CH}_{3}$ bond is favorably considered as the initial step or major route for pyrolytic 
decomposition of CoA, which can be confirmed by the fact that CoA starts to decompose at lower temperature $(773 \mathrm{~K})$ than $\mathrm{CA}$ and $\mathrm{PA}$, as presented in Figure 6a. The simulated conversion of CoA fits the experimental values well.

Figure 7 shows a ROP analysis of CoA pyrolysis performed at $923 \mathrm{~K}$. A simulated conversion rate of $48.7 \%$ is reached at this temperature. Different from above described mechanism, initially $99.4 \%$ of the solid CoA sublimates into the gas phase and is completely consumed via radical chemistry. Homolysis of the weakest $\mathrm{O}-\mathrm{CH}_{3}$ bond accounts for $33.2 \%$ of the total $\mathrm{CoA}$ consumption. CoA also reacts by $\mathrm{H}$-atom abstractions from hydroxyl and aldehyde groups, accounting for $16.2 \%$ and $50.0 \%$, respectively. The formed methyl radicals leads to methane that is predicted well as shown in Figure 6d. The fate of abundant phenoxy-type radicals is not predicted here and they are regarded as one of the main precursors of PAH and coke in lignin pyrolysis and gasification $(25,62-63)$. This is consistent with the incomplete mass closure at high temperatures (Figure S2) which is mainly attributed to the formation of these large molecules that were not detected nor quantified using the Py-GC instrument. This is reaffirmed by the black deposits seen on the quartz tube after the experiments (Figure S3). Another abundant radical $R(C 9)$ can further decompose to $\mathrm{CO}$ which is the major light gas, and 4-vinyl guaiacol radicals. This latter can form 4-vinyl guaiacol, the major aromatic product, via the H-atom abstraction reactions. Similar to the CoA, 4-vinyl guaiacol can be consumed via the homolysis of $\mathrm{O}-\mathrm{CH}_{3}$ bond which is not described in the Figure 7. In Figure 6b, 4-vinyl guaiacol is largely overpredicted at CoA conversion above 27.1\%, whereas $\mathrm{CO}$ (Figure 6c) is underpredicted and this prediction becomes worse with increasing CoA conversion. This dissimilarity is probably occurring from the secondary reactions, which have not been accounted for in the current kinetic model. For example, all 4-vinyl guaiacol radicals lead to 4-vinyl guaiacol in this model, but part of them should also lead to dimers or other oligomers based on the analysis of CA pyrolysis. In addition, 2-hydroxyphenoxy radicals from the demethylation of 4-vinyl guaiacol could react further to form some secondary products such as 4-vinylbenzene-1,2-diol. Here, the formation of CO 
solely arises from the aldehyde group on the side chain, but CO may also results from the further decomposition of phenoxy-type radicals, similar to anisole or guaiacol pyrolysis. Nevertheless, their trends are well predicted by the model. Further study is required to develop a complete and comprehensive kinetic models for guaiacyl lignin model compounds.
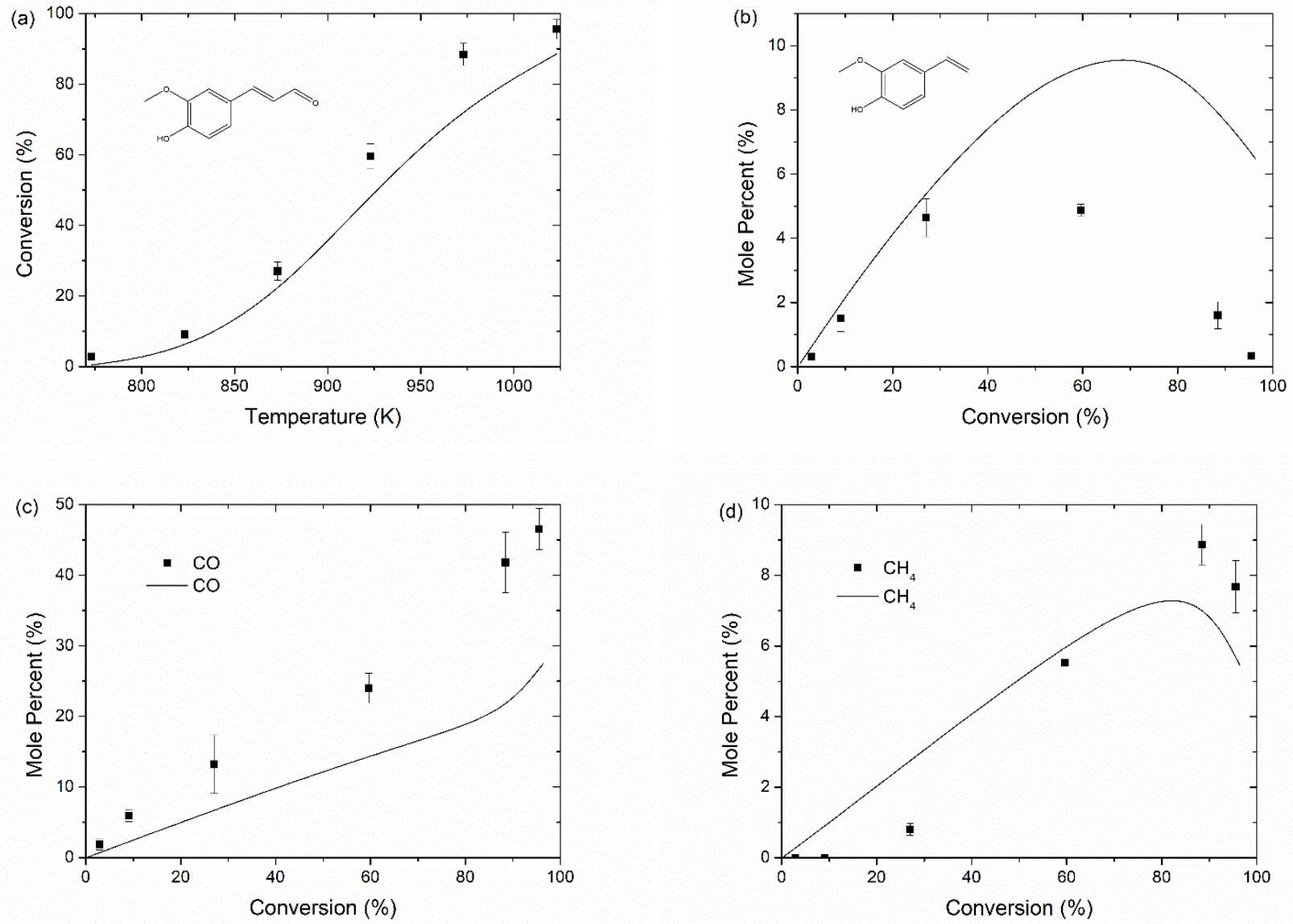

Figure 6. Experimental (symbols) and simulated (lines) conversion of (a) CoA versus reactor temperature, and yields of its primary products $(\mathrm{b}-\mathrm{d})$. 


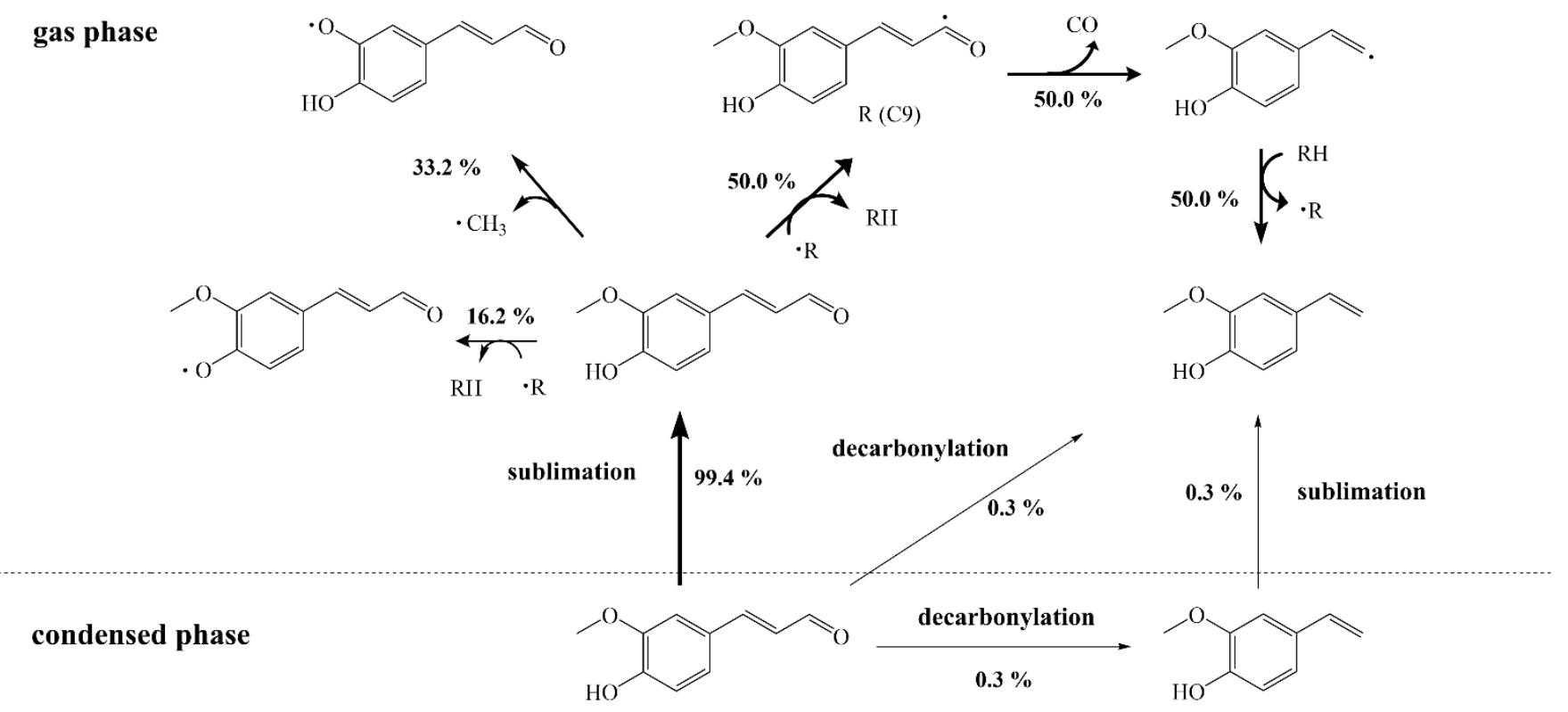

Figure 7. Rate of production analysis for CoA pyrolysis at $923 \mathrm{~K}$. Percentages (numbers associated with arrows) on a reaction path show the reaction rate relative to the consumption of solid CoA.

\section{Conclusions}

The pyrolysis of three hydroxycinnamaldehyde model compounds was studied. The decomposition products of cinnamaldehyde, $p$-coumaraldehyde, and coniferaldehyde were measured in a micropyrolysis unit equipped with a comprehensive analysis section that can detect and quantify pyrolysis products with boiling points up to $823 \mathrm{~K}$ next to permanent gases. The first-principles based kinetic models, consisting of 9,11 and 15 reactions, as well as 10,11 and 15 species for CA, PA and CoA pyrolysis respectively, revealed the major thermal decomposition routes. The simulations were able to predict the experimental trends of the reactants and primary products typically within $\pm 30 \%$ absolute. ROP analysis further revealed that the major thermal decomposition routes of CA and PA are concerted decarbonylation occurring in the condensed phase, though experimental products distribution shows the presence of radical chemistry in CA and PA pyrolysis at higher temperatures. For CoA pyrolysis, the presence of a weak $\mathrm{O}-\mathrm{CH}_{3}$ bond connected to the aromatic ring results in a more dominant radical chemistry in the gas phase. 
ROP analysis of CoA indicated that it mainly decomposes via the $\mathrm{H}$-atom abstraction on the aldehyde group, followed by the homolysis of O-methyl $\left(\mathrm{O}-\mathrm{CH}_{3}\right)$ bond at $923 \mathrm{~K}$. The latter initiates a radical chain mechanism and produces more species. Insights obtained from this study could be useful in developing detailed kinetic mechanisms of pyrolysis or combustion of more complex lignin structures, and guide genetic modifications of biomass to increase the yields of specific chemicals.

\section{Supporting Information}

The following files are available free of charge.

- Overview of the columns used in LOA GC and GC $\times$ GC (Table S1 and 2), LOA GC temperature program (Table S3), GC $\times$ GC settings for the simultaneous FID/TOF-MS analysis (Table S4), kinetic models (separated files in CHEMKIN format) (Text S1), reactor model for the first reactor of the micro-pyrolysis setup (Text S2), GC $\times$ GC FID chromatograms obtained for the pyrolysis of (a) CA at $973 \mathrm{~K}$, (b) PA at $973 \mathrm{~K}$ and (c) CoA at $873 \mathrm{~K}$ (Figure S1), mass balances and molar balances of $\mathrm{C}, \mathrm{H}$ and $\mathrm{O}$ elements for the pyrolysis of CA, PA and CoA (Figure S2), reactor (new) before and (old) after pyrolysis experiments (Figure S3), and products formed from CA, PA and CoA pyrolysis (Table S5-7). (PDF)

- Kinetic model of cinnamaldehyde pyrolysis (TXT)

- Kinetic model of $p$-coumaraldehyde pyrolysis (TXT)

- Kinetic model of coniferaldehyde pyrolysis (TXT)

\section{Author Information}

\section{Corresponding Author}


Kevin M. Van Geem - Laboratory for Chemical Technology, Ghent University, Technologiepark 125, 9052 Zwijnaarde, Belgium;

ORCID http://orcid.org/0000-0003-4191-4960;

Email: Kevin.VanGeem@UGent.be

\section{Authors}

Liang Li - Laboratory for Chemical Technology, Ghent University, Technologiepark 125, 9052 Zwijnaarde, Belgium

Ruben Van de Vijver - Laboratory for Chemical Technology, Ghent University, Technologiepark 125, 9052 Zwijnaarde, Belgium

Andreas Eschenbacher - Laboratory for Chemical Technology, Ghent University, Technologiepark 125, 9052 Zwijnaarde, Belgium

Onur Dogu - Laboratory for Chemical Technology, Ghent University, Technologiepark 125, 9052 Zwijnaarde, Belgium

\section{Notes}

The authors declare no competing financial interest.

\section{Acknowledgments}

Liang Li thanks the financial support from the Overseas Study Program of Guangzhou Elite Project. Ruben Van de Vijver acknowledges financial support from the Fund for Scientific Research Flanders (FWO) grant number 3E013419. This work was carried out using the STEVIN Supercomputer Infrastructure at Ghent University, funded by Ghent University, the Flemish Supercomputer Center (VSC), the Hercules Foundation and the Flemish Government - department EWI. 


\section{References}

1. Biomass Technology Group. https://www.btgworld.com/nl/news.

2. Jacobson, K.; Maheria, K. C.; Dalai, A. K., Bio-oil valorization: a review. Renewable and Sustainable Energy Reviews 2013, 23, 91-106.

3. Mohan, D.; Pittman Jr, C. U.; Steele, P. H., Pyrolysis of wood/biomass for bio-oil: a critical review. Energy \& fuels 2006, 20 (3), 848-889.

4. Mortensen, P. M.; Grunwaldt, J.-D.; Jensen, P. A.; Knudsen, K.; Jensen, A. D., A review of catalytic upgrading of bio-oil to engine fuels. Applied Catalysis A: General 2011, 407 (1-2), 1-19.

5. Mullen, C. A.; Boateng, A. A.; Goldberg, N. M.; Lima, I. M.; Laird, D. A.; Hicks, K. B., Bio-oil and bio-char production from corn cobs and stover by fast pyrolysis. Biomass and bioenergy 2010, 34 (1), 67-74.

6. Guedes, R. E.; Luna, A. S.; Torres, A. R., Operating parameters for bio-oil production in biomass pyrolysis: A review. Journal of analytical and applied pyrolysis 2018, 129, 134-149.

7. Sheldon, R. A., Green and sustainable manufacture of chemicals from biomass: state of the art. Green Chemistry 2014, 16 (3), 950-963.

8. Vanholme, R.; Morreel, K.; Ralph, J.; Boerjan, W., Lignin engineering. Current opinion in plant biology 2008, 11 (3), 278-285.

9. Vanholme, R.; Demedts, B.; Morreel, K.; Ralph, J.; Boerjan, W., Lignin biosynthesis and structure. Plant physiology 2010, 153 (3), 895-905.

10. Boerjan, W.; Ralph, J.; Baucher, M., Lignin biosynthesis. Annual review of plant biology 2003, 54 (1), 519-546.

11. Liu, C.; Deng, Y.; Wu, S.; Mou, H.; Liang, J.; Lei, M., Study on the pyrolysis mechanism of three guaiacyl-type lignin monomeric model compounds. Journal of analytical and applied pyrolysis 2016, $118,123-129$.

12. He, T.; Zhang, Y.; Zhu, Y.; Wen, W.; Pan, Y.; Wu, J.; Wu, J., Pyrolysis mechanism study of lignin model compounds by synchrotron vacuum ultraviolet photoionization mass spectrometry. Energy \& Fuels 2016, 30 (3), 2204-2208.

13. Custodis, V. B.; Hemberger, P.; Ma, Z.; van Bokhoven, J. A., Mechanism of fast pyrolysis of lignin: studying model compounds. The Journal of Physical Chemistry B 2014, 118 (29), 8524-8531.

14. Choi, Y. S.; Singh, R.; Zhang, J.; Balasubramanian, G.; Sturgeon, M. R.; Katahira, R.; Chupka, G.; Beckham, G. T.; Shanks, B. H., Pyrolysis reaction networks for lignin model compounds: unraveling thermal deconstruction of $\beta-\mathrm{O}-4$ and $\alpha-\mathrm{O}-4$ compounds. Green Chemistry 2016, 18 (6), 1762-1773.

15. Yerrayya, A.; Natarajan, U.; Vinu, R., Fast pyrolysis of guaiacol to simple phenols: Experiments, theory and kinetic model. Chemical Engineering Science 2019, 207, 619-630.

16. Venderbosch, R.; Prins, W., Fast pyrolysis technology development. Biofuels, bioproducts and biorefining 2010, 4 (2), 178-208.

17. Bridgwater, A.; Peacocke, G., Fast pyrolysis processes for biomass. Renewable and Sustainable Energy Reviews 2000, 4 (1), 1-73.

18. Beis, S.; Mukkamala, S.; Hill, N.; Joseph, J.; Baker, C.; Jensen, B.; Stemmler, E.; Wheeler, C.; Frederick, B.; Van Heiningen, A., Fast pyrolysis of lignins. BioResources 2010, 5 (3), 1408-1424.

19. Yang, H.-M.; Appari, S.; Kudo, S.; Hayashi, J.-i.; Norinaga, K., Detailed Chemical Kinetic Modeling of Vapor-Phase Reactions of Volatiles Derived from Fast Pyrolysis of Lignin. Industrial \& Engineering Chemistry Research 2015, 54 (27), 6855-6864.

20. Yanez, A. J.; Natarajan, P.; Li, W.; Mabon, R.; Broadbelt, L. J., Coupled structural and kinetic model of lignin fast pyrolysis. Energy \& Fuels 2018, 32 (2), 1822-1830. 
21. Hough, B. R.; Schwartz, D. T.; Pfaendtner, J., Detailed kinetic modeling of lignin pyrolysis for process optimization. Industrial \& Engineering Chemistry Research 2016, 55 (34), 9147-9153.

22. Khachatryan, L.; Adounkpe, J.; Dellinger, B., Formation of phenoxy and cyclopentadienyl radicals from the gas-phase pyrolysis of phenol. The Journal of Physical Chemistry A 2008, 112 (3), 481-487.

23. Yuan, W.; Li, T.; Li, Y.; Zeng, M.; Zhang, Y.; Zou, J.; Cao, C.; Li, W.; Yang, J.; Qi, F., Experimental and kinetic modeling investigation on anisole pyrolysis: Implications on phenoxy and cyclopentadienyl chemistry. Combustion and Flame 2019, 201, 187-199.

24. Wagnon, S. W.; Thion, S.; Nilsson, E. J.; Mehl, M.; Serinyel, Z.; Zhang, K.; Dagaut, P.; Konnov, A. A.; Dayma, G.; Pitz, W. J., Experimental and modeling studies of a biofuel surrogate compound: laminar burning velocities and jet-stirred reactor measurements of anisole. Combustion and Flame 2018, 189, 325-336.

25. Nowakowska, M.; Herbinet, O.; Dufour, A.; Glaude, P.-A., Detailed kinetic study of anisole pyrolysis and oxidation to understand tar formation during biomass combustion and gasification. Combustion and Flame 2014, 161 (6), 1474-1488.

26. Nguyen, T. T.; Mai, T. V.-T.; Huynh, L. K., Detailed kinetic modeling of thermal decomposition of guaiacol-A model compound for biomass lignin. Biomass and Bioenergy 2018, 112, 45-60.

27. Nowakowska, M.; Herbinet, O.; Dufour, A.; Glaude, P.-A., Kinetic study of the pyrolysis and oxidation of guaiacol. The Journal of Physical Chemistry A 2018, 122 (39), 7894-7909.

28. Kotake, T.; Kawamoto, H.; Saka, S., Pyrolysis reactions of coniferyl alcohol as a model of the primary structure formed during lignin pyrolysis. Journal of analytical and applied pyrolysis 2013, 104, 573-584.

29. Khachatryan, L.; Xu, M.-X.; Wu, A.-j.; Pechagin, M.; Asatryan, R., Radicals and molecular products from the gas-phase pyrolysis of lignin model compounds. Cinnamyl alcohol. Journal of analytical and applied pyrolysis 2016, 121, 75-83.

30. Harman-Ware, A. E.; Crocker, M.; Kaur, A. P.; Meier, M. S.; Kato, D.; Lynn, B., PyrolysisGC/MS of sinapyl and coniferyl alcohol. Journal of analytical and applied pyrolysis 2013, 99, 161-169.

31. Asatryan, R.; Bennadji, H.; Bozzelli, J. W.; Ruckenstein, E.; Khachatryan, L., Molecular products and fundamentally based reaction pathways in the gas-phase pyrolysis of the lignin model compound pcoumaryl alcohol. The Journal of Physical Chemistry A 2017, 121 (18), 3352-3371.

32. Asmadi, M.; Kawamoto, H.; Saka, S., Gas-and solid/liquid-phase reactions during pyrolysis of softwood and hardwood lignins. Journal of Analytical and Applied Pyrolysis 2011, 92 (2), 417-425.

33. Mettler, M. S.; Vlachos, D. G.; Dauenhauer, P. J., Top ten fundamental challenges of biomass pyrolysis for biofuels. Energy \& Environmental Science 2012, 5 (7), 7797-7809.

34. Vinu, R.; Broadbelt, L. J., A mechanistic model of fast pyrolysis of glucose-based carbohydrates to predict bio-oil composition. Energy \& Environmental Science 2012, 5 (12), 9808-9826.

35. Zhou, X.; Li, W.; Mabon, R.; Broadbelt, L. J., A mechanistic model of fast pyrolysis of hemicellulose. Energy \& environmental science 2018, 11 (5), 1240-1260.

36. Zhou, X.; Nolte, M. W.; Mayes, H. B.; Shanks, B. H.; Broadbelt, L. J., Experimental and mechanistic modeling of fast pyrolysis of neat glucose-based carbohydrates. 1. Experiments and development of a detailed mechanistic model. Industrial \& Engineering Chemistry Research 2014, 53 (34), 13274-13289.

37. Van Acker, R.; Déjardin, A.; Desmet, S.; Hoengenaert, L.; Vanholme, R.; Morreel, K.; Laurans, F.; Kim, H.; Santoro, N.; Foster, C., Different routes for conifer-and sinapaldehyde and higher saccharification upon deficiency in the dehydrogenase CAD1. Plant physiology 2017, 175 (3), 1018-1039. 38. Özparpucu, M.; Gierlinger, N.; Burgert, I.; Van Acker, R.; Vanholme, R.; Boerjan, W.; Pilate, G.; Déjardin, A.; Rüggeberg, M., The effect of altered lignin composition on mechanical properties of CINNAMYL ALCOHOL DEHYDROGENASE (CAD) deficient poplars. Planta 2018, 247 (4), 887-897. 
39. Anderson, N. A.; Tobimatsu, Y.; Ciesielski, P. N.; Ximenes, E.; Ralph, J.; Donohoe, B. S.; Ladisch, M.; Chapple, C., Manipulation of guaiacyl and syringyl monomer biosynthesis in an Arabidopsis cinnamyl alcohol dehydrogenase mutant results in atypical lignin biosynthesis and modified cell wall structure. The Plant Cell 2015, 27 (8), 2195-2209.

40. Kim, H.; Ralph, J.; Lu, F.; Ralph, S. A.; Boudet, A.-M.; MacKay, J. J.; Sederoff, R. R.; Ito, T.; Kawai, S.; Ohashi, H., NMR analysis of lignins in CAD-deficient plants. Part 1. Incorporation of hydroxycinnamaldehydes and hydroxybenzaldehydes into lignins. Organic \& biomolecular chemistry 2003, 1 (2), 268-281.

41. Toraman, H. E.; Vanholme, R.; Borén, E.; Vanwonterghem, Y.; Djokic, M. R.; Yildiz, G.; Ronsse, F.; Prins, W.; Boerjan, W.; Van Geem, K. M., Potential of genetically engineered hybrid poplar for pyrolytic production of bio-based phenolic compounds. Bioresource technology 2016, 207, 229-236.

42. Toraman, H. E.; Abrahamsson, V.; Vanholme, R.; Van Acker, R.; Ronsse, F.; Pilate, G.; Boerjan, W.; Van Geem, K. M.; Marin, G. B., Application of Py-GC/MS coupled with PARAFAC2 and PLS-DA to study fast pyrolysis of genetically engineered poplars. Journal of Analytical and Applied Pyrolysis 2018, 129, 101-111.

43. SriBala, G.; Toraman, H. E.; Symoens, S.; Déjardin, A.; Pilate, G.; Boerjan, W.; Ronsse, F.; Van Geem, K. M.; Marin, G. B., Analytical Py-GC/MS of Genetically Modified Poplar for the Increased Production of Bio-aromatics. Computational and structural biotechnology journal 2019, 17, 599-610.

44. Li, L.; Van de Vijver, R.; Gorugantu, S. B.; Weng, J.; Van Geem, K., Pyrolysis Study of Cinnamaldehyde Model Compound with Analytical Py-gcx gc-fid/tof-ms. Chemical Engineering Transactions 2020, 79-84.

45. Akazawa, M.; Kojima, Y.; Kato, Y., Reaction mechanisms of pyrolysis of four different phenylpropanoids. US Open Pyrolysis Technol J 2015, 1 (1), 1-12.

46. CANTERA website. https://cantera.org/documentation/docs-2.4/sphinx/html/index.html.

47. Melting and boiling points of model compounds. https://en.wikipedia.org/wiki. http://www.chemspider.com/.

48. SriBala, G.; Van de Vijver, R.; Li, L.; Dogu, O.; Marin, G. B.; Van Geem, K. M., On the primary thermal decomposition pathways of hydroxycinnamic acids. Proceedings of the Combustion Institute 2021, 38 (3), 4207-4214.

49. Van Geem, K. M.; Pyl, S. P.; Reyniers, M.-F.; Vercammen, J.; Beens, J.; Marin, G. B., On-line analysis of complex hydrocarbon mixtures using comprehensive two-dimensional gas chromatography. Journal of Chromatography A 2010, 1217 (43), 6623-6633.

50. Pyl, S. P.; Schietekat, C. M.; Van Geem, K. M.; Reyniers, M.-F.; Vercammen, J.; Beens, J.; Marin, G. B., Rapeseed oil methyl ester pyrolysis: On-line product analysis using comprehensive twodimensional gas chromatography. Journal of Chromatography A 2011, 1218 (21), 3217-3223.

51. Schofield, K., The enigmatic mechanism of the flame ionization detector: Its overlooked implications for fossil fuel combustion modeling. Progress in energy and combustion science 2008, 34 (3), 330-350.

52. Montgomery Jr, J. A.; Frisch, M. J.; Ochterski, J. W.; Petersson, G. A., A complete basis set model chemistry. VI. Use of density functional geometries and frequencies. The Journal of chemical physics 1999, 110 (6), 2822-2827.

53. Frisch, M.; Trucks, G.; Schlegel, H.; Scuseria, G.; Robb, M.; Cheeseman, J.; Scalmani, G.; Barone, V.; Petersson, G.; Nakatsuji, H., Gaussian 16. Gaussian, Inc. Wallingford, CT: 2016.

54. Cavallotti, C.; Cuoci, A.; Faravelli, T.; Frassoldati, A.; Pelucchi, M.; Ranzi, E., Detailed kinetics of pyrolysis and combustion of catechol and guaiacol, as reference components of bio-oil from biomass. 2018. 
55. Ince, A.; Carstensen, H. H.; Sabbe, M.; Reyniers, M. F.; Marin, G. B., Group additive modeling of substituent effects in monocyclic aromatic hydrocarbon radicals. AIChE Journal 2017, 63 (6), 20892106.

56. Pelucchi, M.; Cavallotti, C.; Cuoci, A.; Faravelli, T.; Frassoldati, A.; Ranzi, E., Detailed kinetics of substituted phenolic species in pyrolysis bio-oils. Reaction Chemistry \& Engineering 2019, 4 (3), 490506.

57. Gao, C. W.; Allen, J. W.; Green, W. H.; West, R. H., Reaction Mechanism Generator: Automatic construction of chemical kinetic mechanisms. Computer Physics Communications 2016, 203, 212-225.

58. Pelucchi, M.; Somers, K. P.; Yasunaga, K.; Burke, U.; Frassoldati, A.; Ranzi, E.; Curran, H. J.; Faravelli, T., An experimental and kinetic modeling study of the pyrolysis and oxidation of n-C3C5 aldehydes in shock tubes. Combustion and Flame 2015, 162 (2), 265-286.

59. Bourque, G.; Healy, D.; Curran, H.; Zinner, C.; Kalitan, D.; de Vries, J.; Aul, C.; Petersen, E. In Ignition and flame speed kinetics of two natural gas blends with high levels of heavier hydrocarbons, Turbo Expo: Power for Land, Sea, and Air, 2008; pp 1051-1066.

60. Mulcahy, M.; Williams, D., Reactions of free radicals with aromatic compounds in the gaseous phase. II. Kinetics of the reaction of methyl radicals with phenol. Australian Journal of Chemistry 1965, 18 (1), 20-38.

61. Toraman, H. E. Fast Pyrolysis for the Circular Economy: from Plastic Waste to Genetically Engineered Poplar. Ghent University, 2016.

62. Kawamoto, H., Lignin pyrolysis reactions. Journal of Wood Science 2017, 63 (2), 117-132.

63. Sharma, R. K.; Hajaligol, M. R., Effect of pyrolysis conditions on the formation of polycyclic aromatic hydrocarbons (PAHs) from polyphenolic compounds. Journal of Analytical and Applied Pyrolysis 2003, 66 (1-2), 123-144. 
TOC graphic

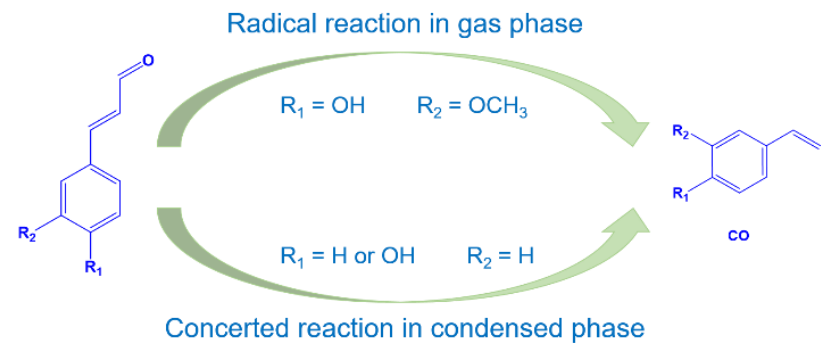

